\title{
'Peering through the window looking in': Postgraduate experiences of non-belonging and belonging in relation to mental health and wellbeing
}

\author{
Dr Charlotte Morris, University of Portsmouth
}

\section{Pre print}

Accepted for publication 28.1.2021 in Studies in graduate and postdoctoral education. [Ahead of print] https://www.emerald.com/insight/content/doi/10.1108/SGPE-07-2020-0055/full/html

\begin{abstract}
This paper explores belonging in relation to postgraduate wellbeing in the light of renewed concerns about the mental health and wellbeing this group of learners. It attends to postgraduates' subjective wellbeing, identifying ways in which this is intertwined with a sense of belonging. Belonging is situated in relation to the social domains of postgraduate experiences. The paper seeks to contribute in-depth understandings of postgraduate experiences, to make recommendations for practice and to identify fruitful paths for further theorisation and research.

Two qualitative data sets situated in UK higher education are drawn on here: Firstly, longitudinal qualitative data entailing 33 narrative interviews and written reflections of doctoral researchers were collected as part of a phenomenological study of doctoral learning. Secondly, interview data from 20 postgraduates (including masters, professional doctorates and $\mathrm{PhD}$ researchers) were collected as part of mixed method qualitative case study research into postgraduate wellbeing. Postgraduate participants were based in the social sciences, humanities, arts and professional disciplines at a cross-section of UK higher education institutions. Data was analysed thematically with a focus on interconnections between wellbeing, learning and belonging.
\end{abstract}

A sense of belonging arose as a key contributing factor to postgraduate wellbeing. Belonging emerged as multi-faceted, interlinking with spatial, relational and cultural factors which are likely to be experienced in different ways and degrees depending on positionalities. Experiences of belonging and non-belonging are understood as produced through academic cultures and structural inequities. They also pertain to the uncertain, in-between position of postgraduate learners. For postgraduates, and doctoral researchers especially, reaching a sense of belonging to academia was a profoundly important aspect of their journeys. Conversely, lack of belonging is linked with poor mental wellbeing and engagement with studies.

This paper engages with the neglected social domain of wellbeing. Attending to subjective perceptions of wellbeing enabled nuanced understandings of the links between wellbeing and belonging. It identifies spatial, relational and cultural dimensions of postgraduate belonging, contributing an understanding of how feelings of non-belonging manifest, how belonging might be nurtured, and how this potentially contributes to postgraduates' wellbeing.

Key words: Postgraduate, wellbeing, belonging 


\section{Introduction}

A sense of belonging to communities of peers, to institutions and wider academic communities is discussed here as key to postgraduate mental wellbeing. Centring the perspectives of postgraduate learners, this paper draws on two UK-based qualitative studies (Wisker, Morris et al., 2010; Morris and Wisker, 2011) focussing on postgraduate experiences, including taught masters-level, parttaught professional doctorates and PhDs. Wide-ranging factors influencing wellbeing were identified: where wellbeing was negatively affected, detrimental personal and academic impacts followed, in some cases triggering episodes of mental ill-health. Research also captured factors which foster wellbeing, including belonging, which emerged as highly significant. This data has recently been reanalysed to gain deeper understandings of postgraduate learning, wellbeing and belonging.

Belonging as a concept eludes simplistic definitions but at its kernel pertains to a felt sense of identifying with and being accepted within a place and/or community, in this instance academia and specific communities within this milieu (White and Noonemaker, 2008). A profoundly human need for interaction has long been recognised (Maslow, 1954). Certain practices may facilitate belonging in relation to identification and acceptance while others create non-belonging through exclusion and devaluation. Spaces, temporalities and communities may foster belonging and /or non-belonging, interacting in complex, shifting ways with lived experiences. Postgraduate learning itself is multifaceted, encompassing environmental, relational, cultural and contextual dimensions. Furthermore, postgraduates' complex lived experiences and identities bely narrow constructions and linear pathways to 'completion'. Many postgraduates balance multiple identities as students, employees and parents (Jazvak-Martek, 2009). Expressions of non-belonging can be traced to conditions specifically affecting postgraduates including uncertain statuses; postgraduates occupy liminal spaces 'in-between' student and fully fledged academic (Morris et al., forthcoming; Morris and Wisker, 2011) which often exposes them to power disparities (Burford and Hook, 2019). Due to the transience of postgraduate populations, sustaining relationships and communities can present challenges. Attending to belonging prompts reflection on the need for more inclusive and equitable academic cultures and practices more broadly. Many postgraduate experiences of (non)belonging are shaped through gendered, classed, raced, aged, ableised and carer positionalities (Burford and Hook, 2019; Carter et al., 2013; Loveday, 2016; Puwar, 2004; Williams et al., 2019; Winchester-Seeto et al., 2014).

Work discussed here (Morris and Wisker, 2011) took the World Health Organisation (WHO) definition of mental wellbeing as a starting point: '... a state of well-being in which every individual realizes his or her own potential, can cope with the normal stresses of life, can work productively and 
fruitfully, and is able to make a contribution to her or his community' (WHO, 2003). This recognises wellbeing as multi-dimensional (Dodge et al., 2012) and enables holistic understandings of wellbeing rather than focussing solely on ill-health. It correlates to 'eudaimonic' notions of wellbeing (Ryan and Deci, 2001) pertaining to human flourishing and realisation. This contrasts with research focussing on prevalence of psychological problems, working within a medical model and applying objective measurement criteria (Dodge et al., 2012). Attending to subjective wellbeing engenders nuanced insights into interrelations with belonging, including how feelings of non-belonging manifest and how belonging might be nurtured (in turn contributing to wellbeing).

\section{Literature review}

Belonging is recognised as an important aspect of student experiences, usually in relation to undergraduates (Read et al., 2010; Thomas, 2012). Mantai (2019) stresses its significance for postgraduate experiences, emphasising the crucial role of social support. One study (Peltonen et al., 2017) correlates lack of social support with burnout - explicitly linking belonging and mental wellbeing. Academic 'socialisation' is viewed as key to scholarly development (Mantai, 2017; McAlpine and Amundsen, 2009). However, some learners feel their identities do not fit with university norms (Mantai, 2019) and many experience isolation (Ali and Kohun, 2006). The importance of community for postgraduates has been theorised in relation to 'communities of practice' (Wenger, 2000; Wisker et al., 2007), understood as the purposeful coming together of people with shared interests in ways which facilitate their development. The term 'community' is used in different ways and holds different meanings for people; postgraduates often belong to multiple communities in which they experience different degrees of belonging (White and Noonemaker, 2008). Postgraduate communities may include peers, research and/or teaching teams, departments, institutions, disciplinary / professional communities or specialist research field(s) spanning International contexts. Experiences of belonging may shift over time as learners move through and between different communities, identities, temporalities and spaces.

Instilling belonging and fostering wellbeing in academia entails addressing structural inequalities: Metcalfe et al. (2018) link poor wellbeing with marginalised positionalities in academia. Experiences of non-belonging often stem from being 'otherised' in such environments (Read et al., 2010). 'Ideal learners' tend to be constructed as white, cis-male, middle-class, young, able-bodied and unencumbered by domestic and caring responsibilities (Lynch et al., 2010; Mirza, 1995), those who do not conform marked as 'non-traditional' (Spurling, 1990). Exclusionary cultures produce feelings of non-belonging among student carers (Marandet and Wainwright, 2010) who may struggle to fit 
into academic cultures where care is seldom visible or valued (Lynch, 2010). Non-belonging to what is typically middle-class habitus is recognised as prevalent among working-class learners (Reay, 1998) and has been linked to ethnicity (Mirza, 1995), gender (Carter et al., 2013) and International postgraduate experiences (Winchester-Seeto et al., 2014). This paper contributes in-depth explorations of postgraduates' experiences and interconnections of belonging and wellbeing, suggesting that non-belonging can impact on wellbeing (and progress); conversely positive feelings of belonging contribute to overall wellbeing, enrich learning experiences and stimulate processes of identification, enabling postgraduates to fully become part of academic communities (Mantai, 2017).

\section{Methodology and Methods}

Two data-sets, utilising data collected by the author within wider projects [1] are drawn on here: Firstly, longitudinal qualitative data was collected for the 'Doctoral Learning Journeys' project (Wisker, Morris et al., 2010); this Higher Education Academy (HEA) funded study adopted a phenomenological paradigm for investigating doctoral experiences. This approach illuminates lived experience of phenomena and seeks to capture and interpret complexities of thought, feeling and interactions, situated in everyday lived experiences (Munhall, 2007; van Manen, 1997). It recognises researchers as embedded in research processes, requiring reflexivity (Polkinghorne, 1989). Deploying mixed qualitative methods, it set out to explore multi-dimensional facets of doctoral learning experiences with the overarching aim of understanding conceptual transformations and how doctoral researchers in humanities, arts, social sciences, health and education experience 'conceptual threshold' crossing (Meyer and Land, 2003), becoming more conceptual in their thinking. One strand, conducted by the author, investigated journeys longitudinally over two years: 33 UK doctoral researchers shared experiences through between one and three in-depth narrative interviews and written reflections. The sample was comprised of 14 men, 19 women, 22 white participants and 11 from a Black, Asian or ethnic minority background, 13 part-time and 20 full-time, 23 home and 10 International students and 11 on taught postgraduate programmes, the rest undertaking PhDs. There was a balance between disciplinary areas with $6-7$ participants in each area. Interviews captured multi-dimensional intellectual, ontological, social and emotional domains of learning journeys. Narrative and thematic analyses drew out shifts and some commonalities of experience.

Alongside this, institutional projects explored ways of supporting student wellbeing (Marshall and Morris, 2011). Specific concerns relating to postgraduate wellbeing emerged (Morris et al., 2011); a further HEA funded project (Morris and Wisker, 2011) sought to investigate this phenomenon in 
more depth, focussing on masters, EdD and PhD students in Education across three case study institutions. This approach enabled in-depth, detailed insights into factors which impacted on postgraduate wellbeing. Methods included a free-text survey of 300 learners, focus groups, workshops and 20 in-depth semi-structured interviews with a balance between masters, EdD and PhDs (6 - 7 in each category). Three-quarters of the interview sample drawn on here were women and just under a third were from Black, Asian or ethnic minority communities. While demographic data on class was not systematically recorded it did occasionally emerge in discussions and is alluded to here where relevant. Each data-set was analysed thematically, corresponding with the process outlined by Braun and Clarke (2006): This involves familiarisation with and immersion in the data; identification of themes through coding; revisiting and refining emergent themes, finally developing a narrative. Findings from data-sets were triangulated to produce overarching themes. Ethics approval was granted from the lead institution: informed consent was sought from participants, they were able to withdraw at any point, confidentiality was maintained and data protection protocols followed.

\section{Findings}

Belonging and non-belonging is explored here in relation to wellbeing; belonging emerges as primarily affected by interrelated spatial, cultural and relational factors, produced within academic contexts. When asked about factors impacting on wellbeing, issues pertaining to belonging frequently arose for participants. Status and identity issues were apparent, especially for mature women who often felt deskilled when returning to learning after occupying professional roles. Status issues were felt more generally in terms of the 'in-between' nature of postgraduate study - not fitting the 'ideal' young student model yet unequal to faculty. In this era of short-term contracts (UCU, 2019) postgraduates may simultaneously be experiencing precarious and exploitative conditions of employment. Many encounter problematic, complex supervisory and collegial relationships (Wisker and Robinson, 2013) and may struggle with individualised modes of learning (Johnson, 2000), all of which can be detrimental to wellbeing. The following section considers how postgraduates' place in the academy is reflected in ways in which they experience spaces and spatialise (non)belonging.

\section{Spaces of (non)belonging}

'Peering through the window looking in' is a highly spatialised depiction of a sense of non-belonging, this metaphor encapsulating such feelings, linked to cultures, norms and spaces of the academy. 
These can feel intimidating and alienating, especially for those long out of studies and used to different environments. Academic environments can be non-diverse, exacerbating feelings of being an outsider for those from ethnic minority communities (Hopwood and Paulson, 2012). Elitist aspects of UK academia (Reay, 1998) are reflected in physical environments and may particularly affect working-class learners and those from ethnic minority or International backgrounds. The extract is from a male, working-class PhD learner from an ethnic minority community (Morris et al., 2011), returning to study after a long break: 'Early on I still felt as if I was a fraud; I still wasn't an academic that I was still just someone trying to fit into this world and this culture, that I was peering through the window looking in at, but wasn't really part of.' Their experience chimes with Reay et al.'s (2010) insights into difficulties of 'fitting in' for working-class learners who may feel uncomfortable within academic habitus. It is simultaneously reflective of the 'in-between' status of postgraduates who (along with early career staff) have not yet fully 'arrived' as academics (Morris et al., forthcoming):

Responding to questions about what impacts on wellbeing, feelings of being 'out of place' emerged for part-time learners attending campus at evenings and weekends and missing a campus community atmosphere, one part-time working-class man explaining that few facilities were open and there was a lack of a 'sense of being welcome'. While taught postgraduates reported benefitting from being part of a community of peers, the part-time mode of study outside times when campuses are busy alongside lack of access to workspaces and facilities undermine belonging. These learners might not necessarily feel that they fit in with their peers. Such experiences were amplified in cases where learners felt different - the 'fish out of water' feeling elucidated in Reay's (1998) work. Here a part-time, taught postgraduate woman related experiences of not fitting in, contrasting with her professional environment:

'I am 10 years out of a loop and I think that's really impacted on my wellbeing because... especially compared with the students who have come straight from their undergraduate degrees who wrote their dissertation a few months ago, who still have it all, you know, on their tip of their tongue, well in the seminars they definitely seem to, and I kind of say what I think because at work I'm used to having meetings with senior managers and having to put my point across...'

Hopwood and Paulson (2012) found that doctoral researchers were frequently given poor spaces and locations in which to work, impacting on wellbeing. They recommended more attention to the significance of spaces as being in 'deep and complex relation to students' work, wider lives and physical and emotional wellbeing' (p.679). Dowling and Mantai (2017) observed that identifications as researchers are bound up with space. Some participants, especially PhD researchers, identified lack of work-space as a significant barrier to progression alongside affecting belonging and wellbeing. This particularly affected parents and carers, further excluding them from full recognition 
as part of their academic communities and reinforcing the invisibilisation of care in the academy (Lynch, 2010). In this next example, a PhD researcher and parent spoke of her reliance on workspaces at university, home-working being impossible; however, spaces provided were unpleasant and impermanent. Chiming with Promaska Na Sakronnakon and Burford's (2020) identification of 'unworkable spaces', many participants spoke of poor environments, sometimes cramped and/or without natural light. It is common for PhD researchers to be relegated to 'hot desk' areas where they cannot leave their belongings or undertake quiet scholarly work (Promaska Na Sakonnakon and Burford, 2020); they may not be prioritised for pleasant, conducive surroundings. In some cases, they have no access to appropriate workspaces or are located away from or marked out as separate to faculty - reinforcing power disparities. Space is not only a practical resource issue but symbolic, feeding into felt senses of 'in-between' statuses, preventing identifications as researchers (Dowling and Mantai, 2017) and reinforcing non-recognition:

'Not having a good physical environment to work in, that has been a problem as well as the use of space. I personally cannot work from home as I've got three children and it's not quiet enough, also I don't get into working mode until I physically leave the house and have a space... The space I have at university is [not ideal] but you feel like, okay l've got a space... but I could be chucked out any day and you don't really know where your place is, my voice is not being heard, I don't feel like anyone is really interested in my work... It's the in-between position of a PhD student that can be unpleasant.' (Full-time PhD, mixed race woman)

Yet being physically present on campus does not suit all learners who may need to work from home (Burford and Hook, 2019); alternative routes to belonging, including virtual spaces, need to be considered for part-time, distance learners and those unable to physically attend due to disabilities, health or caring responsibilities. Conversely, a masters-level learner spoke of negative impacts on physical and mental wellbeing of trying to work in a cramped home environment which again highlights inequities; some learners simply do not have the option of comfortable homeworking spaces. Provision of suitable spaces supports wellbeing and belonging, enables identification with others undergoing similar experiences (Dowling and Mantai, 2017) and provides opportunities for informal knowledge exchange and emotional support:

'I really value my shared office and having that structured space then I do feel like I've got a work identity when I go there, I've got a desk and I go to work and for me it's really good to be surrounded by other PhD students who you can talk to as part of that shared space and they support me when things aren't going very well but they also make life enjoyable and fulfilling.' (Full-time PhD, white woman)

While there is recognition of the links between social dimensions of student experiences and learning (Tinto, 1998), the focus tends to be on undergraduates who have structured opportunities to meet in taught contexts and campus spaces orientated to their needs. The importance of spaces specifically allocated for postgraduates, both quiet study spaces and areas where they can socialise 
(Promaska Na Sakonnakon and Burford, 2020), requires further attention. Such spaces, alongside facilitating academic and emotional support, potentially offer conducive environments to foster communities of practice and bolster postgraduate identity, visibility and voice in institutions. Promaska Na Sakonnakon and Burford (2020) note the importance of 'homely' spaces for postgraduates. Yet, as this learner identifies, newer academic buildings tend to favour impersonal open plan spaces - described here as 'airport lounges' - which are neither 'homely' or conducive to confidential, supportive discussions:

'Something that doesn't seem to be valued at all in the fabric of the institution anymore is appropriate social meeting space - not airport lounges. To have a little common room or something, a little social space where students who are based on this site know they can go to have a drink and meet other students who are also research students and... let off steam, whatever it is...' (Part-time $\mathrm{PhD}$, white man)

Closely aligned to spaces themselves was the importance of feeling welcome and the key role everyone in the institution has to play in this, contrasting with experiences where learners felt their lower status in the department was reflected in rude and dismissive attitudes of administrative staff. It is important to note that cultural factors are likely to come into play in terms of who 'fits' in any given group or department and so the importance of actively fostering welcoming, inclusive environments cannot be underestimated:

'The weekend admin was very polite and was very kind and there was a couple of people that, you know, you wouldn't have necessarily have gone and started a conversation with but everyone had time for one, which was fantastic. I think people should be more aware of how little things make a big difference to certain people.' (Part-time, part-taught postgraduate, white working-class man)

\section{Unsettled statuses and non-belonging}

Feelings of non-belonging closely align then with being 'out of place', interlinking with challenges around status. In the context of discussions around wellbeing, postgraduates often reported sensed low statuses in comparison with academic colleagues, sometimes classed as students with little differentiation from undergraduates. As discussed, poor provision of spaces exacerbates nonbelonging and 'initial isolation as I am not part of an academic establishment'. This uncertain status can be unsettling - not student or staff but somewhere in-between (Morris et al., forthcoming): 'You're not part of the staff but you're not like an undergraduate who goes in and does what they're told. So, you're in this kind of... this can be quite unsettling and it can influence and disrupt your work as well' (Part-time PhD, white man).

Such factors unsettle identities and affect confidence with repercussions for wellbeing, especially for those used to being perceived as high-status professionals as encapsulated in this quote from a part- 
time taught postgraduate woman: 'Feeling deskilled having come from a job I knew exceptionally well and was at a high level in my field, to feeling like I know nothing at all!' Mature professional women and carers returning to education strongly felt this 'deskilling' effect; a sudden lack of voice, recognition, ownership and power in institutions was felt keenly by those used to commanding respect. Such de-skilling is often gendered, augmented by academic environments experienced as masculinised (Carter et al., 2013). This also speaks to reductive, linear notions of learning journeys and careers (Puwar, 2004) which seldom fit with complex lived realities of postgraduate lives (Burford and Hook, 2019).

Shifting environments, cultures and staff can feel unsettling and disorientating against a backdrop of continual restructuring in line with neoliberal priorities. For postgraduates, this can augment feelings of being 'out of place' and detached from academia, especially where there are poor lines of communication, poor postgraduate community cohesion and lack of opportunities for representation and to affect change:

'The environment has changed from when I started... It's gone through a lot of changes. First the department had one way it was run then it changed, the head of department changed and the whole ethics of the place changed and now it's changed from a department to a School, a merger of two faculties, it's a non-entity... But as a student it's been a bit blown with the wind. I haven't felt personally part of a bigger group where we knew what was going on or had any influence in what is going on... we just had to adapt to it, whatever is happening.' (Full-time PhD, white woman) Particular challenges around status emerged for those occupying dual staff / student identities (Smith et al., 2020) often within the same department, contributing to uncertainties around place in institutional hierarchies. Sometimes this led to role confusion, a consciousness of 'wearing different hats' at different times and in different locations. In some cases, exploitative situations emerged wherein participants felt unable to decline work (paid or unpaid) due to their student status and low positioning in academic hierarchies. Disclosures of bullying from supervisors and line managers reflected wider 'toxic' academic cultures (Gill, 2010) produced by highly pressured neoliberal and inequitable environments. Instances where a participant's line manager was also their supervisor created further complexities (Smith et al., 2020). Fears about saying 'no' reflect widespread academic precarity (UCU, 2019) and cultures of overwork (Gill, 2010). In the following case these factors contributed to severe burnout and exacerbation of underlying mental health difficulties:

'I mean I have been ill... I couldn't say it's as a consequence of just being a student but being a student and working at the same time. I've definitely been ill just as a consequence of being exhausted from pulling those two things together. So that's kind of physically, but... mentally it's very draining and it can also be hard when you work here and you're a student here.' (Part-time PhD, white woman) 


\section{Belonging as relational}

Postgraduates balance multiple relationships - with supervisors, peers, families and wider communities. Social dimensions of experiences came to the fore when participants shared perceptions of factors contributing to wellbeing. Many conveyed that community belonging was paramount to wellbeing: Conversely, in one survey (Morris and Wisker, 2011) isolation arose most frequently in terms of what impacted negatively on wellbeing. Strong communities of peers (of fellow postgraduates, academics in the department and in wider fields of study) foster normalisation of what can be discomforting learning experiences (Wisker, Morris et al., 2010), provide support and facilitate identifications (Dowling and Mantai, 2017). Contrastingly, isolation can be especially acute for doctoral researchers who may work alone in solitary spaces with implications for wellbeing (Dowling and Mantai, 2017) and, as expressed here, motivation:

'I think you can be just very isolated and live a very insular sort of existence here. I mean when I've got real writing and stuff to do I just work at home. I've been in my office all day today and I haven't spoken to anybody, you know, and that's fine cos' I've got absolutely loads to do so I've just been getting on with it but it doesn't kind of fire you up.' (Full-time PhD, white man)

Feelings of disconnection resulting from transient communities were voiced. In contrast, talking through research issues with peers provide important opportunities for learning alongside mutual wellbeing support, and so these were highly valued. The following quote sheds light on the importance of inter-disciplinary opportunities: Yet disciplines are often marked out by physical and cultural boundaries - located in 'the next building along' - which further inhibit personal and academic connections and relationships being forged:

'People have gone away for field work and don't necessarily come back to be based here; people are based where they're from so I feel quite disconnected within my department, and then on a broader scale because [this discipline] is separate from for example social science the sort of institutional boundaries, which have prevented me from getting to know PhDs from other disciplines even though my research is $X$ but because that's the next building along I haven't been able to build up the relationships that I would have liked to so it's been a bit frustrating.' (Full-time PhD, mixed race woman)

There were many expressions of wanting more opportunities for connection, sociality and collegiality within and between disciplines and at every level as a strategy to enhance wellbeing. The following quotation stresses the importance of developing collegiality among and between staff and students, envisaging non-hierarchical environments where mutual knowledge exchange and socialising at all levels are supported:

'Whether it's a physical space within the department or just after a seminar, have a little social for people to keep up on with what you're doing and also... lots of informal discussions, building relationships between staff and students and between staff then if I left... when I returned I could just slot back in, if there's that community already there... When I become an academic I'll want to be in 
an environment where me and my colleagues will discuss what we're doing, with students as well and with researchers.' (part-time PhD, white woman)

However, there were perceived barriers to such communities flourishing. While learners themselves often initiated peer-to-peer opportunities, this was considered unsustainable due to the amount of work and resources involved. Ideally institutional support would be provided while harnessing the creativity and leadership of postgraduates themselves. Postgraduates described their hopes for a distinct community, so that their specific concerns and experiences are recognised and supported:

'What would help a lot would be if the meetings and relationships between PhD students were actually more actively encouraged. What's happening is a lot off the back of students' own organising. It hasn't been facilitated and it hasn't been encouraged. Sometimes it is discouraged and it is such a solitary endeavour but you've got common problems. To be part of a learning community, to have more everyday contact and discussion and learning together then sharing your difficulties and talking to other people, I think that would be a lot more useful.' (Full-time PhD, white man) It was also important for postgraduates to feel fully included in departmental and institutional research communities. However, many experienced barriers to this, particularly for those with younger children and other caring responsibilities and/or disabilities and health conditions. It was frustrating when research and departmental events were scheduled at inconvenient times; in one case events were always held in evenings making it stressful if not impossible to attend. While there are challenges in scheduling events, varying times and being aware that evenings will be especially difficult for parents is a way forward. For this learner, exclusions operated through temporalities as well as spaces, with normative assumptions made about availability, reflecting assumptions of academics as unencumbered with caring responsibilities (Lynch, 2010):

'What can you do? You can't expect anybody to pick up your child from school and have them 'til seven o'clock in the evening... also my son has to do his homework and have his supper and it's just... I do it on the rare occasion but I've sometimes been like a crazy person, I've left here at half-past three, driven to the school, picked my son up, driven him to my parents, driven back to the university just in time for the session - you can't possibly live like that.' (part-time PhD, white woman)

Encouragement and support for conference attendance was viewed as essential for a sense of belonging to wider academia. One mature working-class woman who had returned to study after a long break struggled with confidence, chiming with experiences of many postgraduate returners who began to doubt their abilities. This PhD researcher reported feelings of not being 'good enough' for academia; imposter syndrome is a widely reported response linked to contemporary working and learning conditions in academia (Breeze, 2018; Morris et al., forthcoming). Feelings of deficiency have been found to particularly affect working-class academics (Loveday, 2016). Nevertheless, opportunities to attend conferences and identify with peers made a difference; her sense of belonging increased through positive interactions and identifications with others having similar experiences: 
'Seeing that all the insecurities you have, other people have makes you feel a bit better because quite a few PhD student think "Oh I can't do this, I'm not clever enough, I'm not good enough, I'm not academic enough" but you can see other people going through it and people who've been through it and got out the other end and they still have their doubts... personally that made me feel a lot better, a lot more secure about what I was doing so I got a lot out of presenting at conferences - that made me feel yes I could do this, I could pretend to be an academic.' (Part-time PhD, white woman)

Supervisors play an important role in facilitating belonging to wider academic communities. One International PhD learner struggled initially, due to a combination of culture shock, language barriers, emotional challenges and single parent status. What made a crucial difference to her wellbeing, alongside support for language and her welfare needs being addressed, was feeling welcomed, accepted and valued within her communities (departmental, institutional and disciplinary) as facilitated by her supervisor - she noted that the level of support she received was unusual:

'My supervisor tried to host me, to help me adjust to the environment... when I arrived here he introduced me to department, to his colleague, to make me familiar with everything. He helped me engage with students, he encouraged me to attend research meeting, he encouraged me to attend conference. I felt so scared of everything so he says, "Ok, you can go with us" and he introduced me to so many people at the conference. After that, he encouraged me to present at an [International] conference and introduced me to so many people for networking.' (Full-time International PhD, woman of colour)

Responses often challenged "ivory tower" conceptions of academia and assumptions of an autonomous, isolated research student (Johnson et al., 2000) which reflect western individualised constructions of knowledge. Rather, participants highlighted the shared nature of knowledge creation and centrality of interaction and dialogue with others. This PhD researcher, responding to questions around wellbeing, suggested a need for culture change to reflect the importance of community. Academic culture and constructions of PhDs in particular as solitary individualised journeys can inhibit belonging:

'I think the problem is that too much of the PhD experience is weighted towards... going to the library, come back in three years and you have your PhD and not enough of the recognition that through your data collection, through conferences you attend, through correspondence with other people, through supervision sessions that it is not a solo act but a collective [offering] of knowledge but we just don't have that recognised ... I think that kind of cultural issue is at the heart of why a lot of students experience social isolation and a lack of a sense of belonging to community.' (Part-time $\mathrm{PhD}$, white man)

Moving away from individualised paradigms of postgraduate learning towards recognising interdependencies as essential to knowledge creation and dissemination, could go a long way towards enabling belonging. Also key is recognising the valuable contributions postgraduates make to academic life. Achieving belonging, acceptance and recognition was experienced as a profound shift in learning journeys, often expressed in terms of joy, excitement and renewed motivation. One 
doctoral researcher identified that feeling part of their department transformed how they felt about their studies as they began to engage in dialogue and contribute to discussions, through a departmental seminar series and research centre. Another identified that 'taking part in the conversation' as an equal academic peer was a positive outcome for them in terms of both learning and wellbeing: Alongside crossing conceptual threshold in their learning (Wisker, Morris et al., 2010), postgraduates may also cross cultural thresholds in finding their place in academic communities and can be facilitated to do so.

\section{Conclusion}

This paper illuminates links between postgraduate wellbeing and belonging, identifying belonging as a significant contributing factor to wellbeing with further implications for engagement and progression of postgraduate learners. It contributes understandings of how belonging and nonbelonging are experienced and what this might mean for postgraduate wellbeing, suggesting ways forward for those involved in their support. Belonging emerged as a multi-faceted phenomenon encompassing spatial, relational and cultural factors experienced in different ways and degrees depending on positionalities. Universities and practitioners involved in postgraduate support should recognise and seek to address issues of belonging which require resources, facilitation and support. Feelings of wellbeing intertwined with belonging; this was supported through identification with other learners; recognition of postgraduates as an important constituent of the university; resource needs being met; appropriate spaces provided for mutual support and community building; contributions being valued and equal treatment as peers in academic settings. Working towards inclusive communities of practice (Wisker et al., 2007), offers one way forward for the enhancement of postgraduate wellbeing and belonging. Conversely, non-belonging can lead to negative impacts on wellbeing and consequently progression: Poor environments, uncertain statuses, exclusionary practices, unequal relationships and isolation mar learners' wellbeing, in some cases contributing to episodes of poor mental health. This underlines the importance of attending to social facets of postgraduate wellbeing and meeting universities' duty of care to these learners. Different modes of study have implications, with $\mathrm{PhD}$ researchers being at particular risk of isolation. However, while taught postgraduates benefit from regular contact with peers, they can experience a lack of belonging to their group and to the institution and so awareness of specificities of positionality and experience is vital.

The paper indicates that institutions and those working with postgraduate researchers should take account of the multi-faceted needs of diverse learners in order to promote belonging and wellbeing. 
When learners feel isolated, excluded, under-valued, unrecognised, under-resourced and occupying an uncertain or inferior status as postgraduates and /or due to gendered, raced, classed positionalities, this can be detrimental to wellbeing. Non-belonging particularly affects postgraduates with marginalised identities as the spaces, temporalities and cultures of academia are often forged around limiting assumptions about learners, their identities, journeys and experiences. A range of cultural and material factors come into play in producing exclusions, including discrimination and lack of resources (Williams et al., 2019) and so these structural dimensions require attention. Lack of belonging contributes to demotivation, burnout and lack of progress and so it is imperative this is recognised and addressed by practitioners and university leaders. Relatively simple steps could be taken to provide inclusive spaces and adequate resources, foster collegial relationships and ensure all members of academic communities receive equal treatment. Alongside impacts on individual learners, there are serious implications for institutions, for future knowledge creation capacity and for meeting wider equity goals if crucial social facets of experience are neglected. Further research is recommended in terms of theorising postgraduate belonging and its interrelation with wellbeing alongside identification of policy and practice interventions. Research could usefully attend to ways in which temporal, spatial, intellectual and social boundaries and hierarchies are drawn in academic cultures and how these might be dismantled. Ultimately, the prioritisation of building more inclusive academic communities which are responsive to diverse needs will go a long way towards addressing contemporary postgraduate wellbeing challenges.

\section{Notes}

[1] Please note, permission was obtained from the projects' Principal Investigator and former Director of Centre for Learning and Teaching, University of Brighton to reanalyse and present this data. Some of the data and findings pertaining to student experiences were originally published in project reports and internal publications.

\section{Acknowledgements}

I would like to thank Professor Gina Wisker for the opportunity to work on these fascinating projects and for enabling me to revisit and undertake further analysis on this data in the light of renewed concerns surrounding postgraduate wellbeing. Thanks are due to all those who participated and gave generously of their time. Finally, thank you to my colleague Professor Jane Creaton for editing this special issue; the helpful advice and comments from the anonymous reviewers are appreciated. Dr James Burford kindly offered advice and support on an early draft of this article.

Funding: The original research was funded by the Higher Education Academy

\section{References}

Ali, A. and Kohun, F. (2006). "Dealing with isolation feelings in IS doctoral programs", International Journal of Doctoral Studies, Vol. 1, pp. 21-33. 
Braun, V. and Clarke, V. (2006). Using thematic analysis in psychology, Qualitative Research in Psychology, Vol. 3 No. 2, pp. 77-101.

Burford, J. and Hook, G. (2019) "Curating care-full spaces: doctoral students negotiating study from home", Higher Education Research \& Development, Vol. 38 No. 7, pp. 1343-1355.

Carter, S., Blumenstein, M., and Cook, C. (2013). "Different for women? The challenges of doctoral studies", Teaching in Higher Education, Vol. 18, No. 4, pp. 339-351.

Dodge, R., Daly, A., Huyton, J., \& Sanders, L. (2012). "The challenge of defining wellbeing", International Journal of Wellbeing, Vol. 2 No. 3, pp. 222-235.

Dowling, T. and Mantai, L. (2017). "Placing researcher identifications: labs, offices and homes in the PhD", Area, Vol. 49 No. 2, pp. 200-207.

Gill, R. (2009). "Breaking the silence: The hidden injuries of neo-liberal academia" in Flood, R. and Gill, R. (Ed.s.) (2009) Secrecy and Silence in the Research Process: Feminist Reflections. London: Routledge

Hitch, D., Pépin, G., \& Stagnitti, K. (2014). “In the footsteps of Wilcock, part two: The interdependent nature of doing, being, becoming, and belonging", Occupational Therapy in Health Care, Vol. 28, No. 3, pp. 247-263.

Hopwood, N. and Paulson, J. (2012). "Bodies in narratives of doctoral students' learning and experience", Studies in Higher Education, Vol. 37 No. 6, pp. 667-681.

Jazvac-Martek, M. (2009). “Oscillating role identities: The academic experiences of education doctoral students", Innovations in Education and Teaching International, Vol. 46 No. 3, pp. 253-264. Johnson, L., Lee, A. and Green, B. (2000). "The PhD and the Autonomous Self: Gender, rationality and postgraduate pedagogy", Studies in Higher Education, Vol. 25 No. 2, pp. 135-147.

Lynch, K. (2010). "Carelessness: A hidden doxa of higher education", Arts and Humanities in Higher Education, Vol. 9 No.1, pp. 54-67.

Loveday, V. (2016). “Embodying deficiency through 'affective practice': Shame, relationality, and the lived experience of social class and gender in higher education." Sociology, Vol. 50 No 6, pp. 11401155.

Mantai, L. (2019). “'A Source of Sanity': The role of social support for doctoral candidates' belonging and becoming", International Journal of Doctoral Studies, Vol. 14 Issue 1, pp. 367-382. 
Marandet, E. and Wainwright, E. (2010). "Invisible experiences: understanding the choices and needs of university students with dependent children", British Educational Research Journal, Vol. 36 No. 5, pp. 787-805.

Marshall, L. and Morris, C. (Ed.s.) (2011). Taking Wellbeing Forward in Higher Education: Reflections on Theory and Practice, University of Brighton Press, Brighton.

https://staff.brighton.ac.uk/clt/published/wellbeing in higher ed screen1.pdf

Maslow, A. H. (1954). Motivation and personality. Harper \& Row, New York.

McAlpine, L. and Amundsen, C. (2009). "Identity and agency: Pleasures and collegiality among the challenges of the doctoral journey", Studies in Continuing Education, Vol. 31, No. 2, pp. 109-125.

Metcalfe, J., Wilson, S. and Levecque, K. (2018). Exploring wellbeing and mental health and associated support services for postgraduate researchers. Vitae, Cambridge.

Meyer, J.H.F. and Land, R. (2003). "Threshold concepts and troublesome knowledge: Linkages to ways of thinking and practicing within disciplines", ESRC Occasional Report, No. 4., Swindon.

Mirza, H.S. (1995). "Black women in higher education: defining a space/finding a place", in Morley, L. and Walsh, V. (Ed.s) Feminist Academics: creative agents for change. Taylor \& Francis, London.

Morris, C. Kadiwal, L., Telling, K., Ashall, W., Kirby, J., Mwale, S. (forthcoming) Restorying imposter syndrome in the Early Career stage: reflections, recognitions and resistance, in Addison, M., Breeze, M. and Taylor, Y. (Ed.s.) Handbook of Imposter Syndrome in Higher Education. Palgrave Macmillan, New York.

Morris, C. and Wisker, G. (2011). Troublesome Encounters: Strategies for managing the wellbeing of Postgraduate Education students during their learning processes. Escalate, Bristol.

Morris, C. (2011). "Wellbeing and the Research Student" in Marshall, L. and Morris, C. (Ed.s.) (2011) Taking Wellbeing Forward in Higher Education: Reflections on Theory and Practice, University of Brighton Press, Brighton.

Peltonen, J.A., Vekkaila, J., Rautio, P., Haverinen, K. \& Pyhältö, K. (2017). “Doctoral students' social support profiles and their relationship to burnout, drop-out intentions, and time to candidacy", International Journal of Doctoral Studies, Vol. 12, pp. 157-173.

Polkinghorne, D.E. (1989). "Phenomenological research methods" in R. S. Valle and S. Halling (Ed.s.) (1989). Existential-phenomenological perspectives in psychology (pp. 41-60). Plenum, New York. 
Promsaka Na Sakonnakron, S. and Burford, J. (2020). “Doctoral Students' Readings of the Politics of University Office Space", New Zealand Journal of Educational Studies, Vol. No. 55, pp. 165-180.

Puwar, N. (2004). Space Invaders: Race, Gender and Bodies Out of Place. Bloomsbury, London.

Read, B., Archer, L. \& Leathwood, C. (2003). “Challenging cultures? Student conceptions of "belonging" and "isolation" at a post-1992 university", Studies in Higher Education, Vol. 28 No.3, pp. 261-277.

Reay, D. (1998). “'Always knowing' and 'never being sure': familial and institutional habituses and higher education choice", Journal of Education Policy, Vol. 13, pp. 519-529.

Ryan, R. and Deci, E. (2001) "On happiness and human potentials: A review of research on hedonic and eudaimonic wellbeing", Annual Review of Psychology, Vol. 52, pp. $141-166$.

Smith, J., Billot, J., Clouder, L. \& King, V. (2020) “Juggling competing activities: academic staff as doctoral candidates", Higher Education Research \& Development, Vol. 39 No. 3, pp. 591-605

Spurling, A. (1990). Women in Higher Education. King's College Research Centre, Cambridge. Thomas, L. (2012). Building Student Engagement and Belonging in Higher Education at a Time of Change. Paul Hamlyn Foundation, London.

Tinto, V. (1998). "Colleges as Communities: Taking Research on Student Persistence Seriously", The Review of Higher Education, Vol. 21 No.2, pp. 167-177.

UCU (Universities and Colleges Union). 2019. Counting the costs of casualisation in higher education. UCU, London.

van Manen, M. (1997). "Researching lived experience: Human science for an action sensitive pedagogy". The Althouse Press, London, Ontario.

World Health Organisation (2003). Investing in Mental Health. Department of Mental Health and Substance Dependence, Noncommunicable Diseases and Mental Health, World Health Organization, Geneva.

Wenger, E. (2000). "Communities of Practice and Social Learning Systems", Organization, Vol. 7 No. 2, pp. 225-246.

White, J. and Nonnamaker, J. (2008). "Belonging and Mattering: How Doctoral Students Experience Community", NASPA Journal, Vol. 45 No. 3, pp. 350-372. 
Williams, P., Bath, S., Arday, J. \& Lewis, C. (2019). The Broken Pipeline Report: Barriers to Black PhD Students Accessing Research Council Funding. Leading Routes, UK.

Winchester-Seeto, T., Homewood, J., Thogersen, J., Jacenyik-Trawoger, C., Manathunga, C., Reid, A., and Holbrook, A. (2014). "Doctoral supervision in a cross-cultural context: Issues affecting supervisors and candidates", Higher Education Research \& Development, Vol. 33 No.3, pp. 610-626. Wisker, G. and Robinson, G. (2013). “Doctoral 'orphans': nurturing and supporting the success of postgraduates who have lost their supervisors", Higher Education Research \& Development, Vol. 32 No. 2, pp. 300-313.

Wisker, G., Robinson, G. \& Shacham, M. (2007). “Postgraduate research success: Communities of practice involving cohorts, guardian supervisors and online communities", Innovations in Education and Teaching International, Vol. 44 No. 3, pp. 301-320.

Wisker, G., Morris, C., Cheng, M., Masika, R., Warner, M., Trafford, V., Robinson, G. and Lilly, J. (2010). Doctoral Learning Journeys Final Report. Higher Education Academy National Teaching Fellowship Scheme Project, UK.

\section{Note}

Please note, permission was obtained from the Principal Investigator and Director of Centre for Learning and Teaching, University of Brighton, to reanalyse and present this data. Some of the data and findings pertaining to student experiences were originally published in project reports and internal publications.

\section{Licensing statement}

Emerald allows authors to deposit their AAM under the Creative Commons Attribution Noncommercial International Licence 4.0 (CC BY-NC 4.0). The AAM is deposited under this licence and that any reuse is allowed in accordance with the terms outlined by the licence. To reuse the AAM for commercial purposes, permission should be sought by contacting permissions@emeraldinsight.com.

(C) Emerald Publishing Limited 2398-4686 
